\title{
The Nature of the Self, Self-regulation and Moral Action: Implications from the Confucian Relational Self and Buddhist Non-self
}

\author{
Irene $\mathrm{Chu}^{1} \cdot$ Mai $\mathrm{Chi} \mathrm{Vu}^{2}$ (]
}

Received: 31 March 2019 / Accepted: 20 April 2021 / Published online: 12 May 2021

(c) The Author(s) 2021

\begin{abstract}
The concept of the self and its relation to moral action is complex and subject to varying interpretations, not only between different academic disciplines but also across time and space. This paper presents empirical evidence from a cross-cultural study on the Buddhist and Confucian notions of self in SMEs in Vietnam and Taiwan. The study employs Hwang's Mandala Model of the Self, and its extension into Shiah's non-self-model, to interpret how these two Eastern philosophical representations of the self, the Confucian relational self and Buddhist non-self, can lead to moral action. By demonstrating the strengths of the model, emphasizing how social and cultural influences constrain the individual self and promote the social person leading to moral action, the paper extends understanding of the self with empirical evidence of the mechanisms involved in organizational contexts.
\end{abstract}

Keywords Moral action $\cdot$ Relational self $\cdot$ Non-self $\cdot$ Confucianism $\cdot$ Buddhism $\cdot$ Mandela Model of the Self

\section{Introduction}

The notion of the self and processes involving its regulation can significantly shape moral behaviours (for example Aquino et al., 2009; Joosten et al., 2014; Sachdeva et al., 2009). Studies show that people who consider the concept of the self as salient display more prosocial behaviours than those who do not (Aquino et al., 2009; Jordan et al., 2011; Reed et al., 2007). However, the dominant models in the literature focus on the self more as an individualistic rather than a social concept (for example Blasi, 1983; Kohlberg, 1984; Piaget, 1932/1977; Rest, 1983). Scholars acknowledge such interpretations as potential imaginary views of a definite self (Alvesson \& Robertson, 2016; Brown, 2019; Driver, 2005), demonstrating a focus on individualistic, idealized interpretations of self-centeredness. In response, in this

Irene Chu

i.chu@bradford.ac.uk

Mai Chi Vu

mai.c.vu@northumbria.ac.uk

1 University of Bradford, School of Management, Bright Building, Bradford BD7 1SR, UK

2 Northumbria University, Newcastle Business School, Sutherland Building, 2 Ellison Pl, Newcastle upon Tyne NE1 8ST, UK study, we draw from a broader philosophical understanding of the self by exploring interpretations from different cultural perspectives. Using examples from empirical case studies involving the Confucian relational self and Buddhist non-self, we show how an alternative model (Hwang, 2011) demonstrates how moral action can be fostered by constraint of the individual.

There are a number of reasons for this approach. First, both Buddhism and Confucianism are widely acknowledged as important philosophies that promote virtues and ethical values. For instance, Buddhism stresses the "moral, ethical, value-based, scientific, educational system, the goal of which is to allow the individual to discover the true nature of things" (Johansen \& Gopalakrishna, 2006, p. 238). Similarly, Confucianism promotes the moral cultivation of both the self and the helping of others to attain a purposeful life sustained by virtue in order to achieve social harmony (Lin et al., 2013; Yu, 2007). Both the relational self and nonself emphasize the importance of humanity and the ethical foundations of the self. Second, we explore how these deeply held ethical values can address concerns relating to moral action (Bazerman \& Sezer, 2016; DeTienne et al., 2019; Paik et al., 2019). Third, while there are studies examining non-self and the relational self, most of these examine the concepts separately or in limited depth without empirical data (for example Hwang \& Chang, 2009; Shiah, 2016). 
To explore how the notions of the relational self and non-self facilitate moral action, our paper summarizes two qualitative exploratory case studies conducted on small and medium-sized enterprises (SMEs) in Taiwan with Confucian values and Vietnam with engaged Buddhism. We examined SMEs since there is relatively little research on ethical decision making within them, although they may be more ethical than larger organizations due to the relatively greater influence of the founder within them (Crockett, 2005). SMEs may also shed light on ethical dilemmas through the dynamic interplay between personal construction of moral principles and engagement in moral intent and behaviour (Savur et al., 2018). The findings are interpreted using the Mandala Model of the Self (MMS) proposed by Hwang (2011) for a number of reasons. First, this model moves away from fixed universal notions of morality since it allows interpretations from various cultures and traditions. Aspects of social identity are taken more fully into account than alternative models because the relationship between the individual and their cultural traditions are considered. Second, the MMS has been used as a basis for the development of a theory of the Buddhist non-self by Shiah (2016), demonstrating its applicability to different cultures. Third, such models remain largely abstract (DeTienne et al., 2019) and so can benefit from futher support from empirical studies. We explore transcultural interpretations of the self through an investigation of the distinctive features of the relational self and non-self and so shed light on how these can influence ethical behaviours in organizational contexts. However, we do not suggest that the actions of people in Taiwan and Vietnam are completely driven by the Confucian relational self or the Buddhist non-self respectively. Rather, these should be viewed in the same way as Weber's ideal types, that is as abstract representations of nevertheless real characteristics forming parts of a unified analytical construct (Brubaker, 1984).

The findings from the study broadly support the MMS in that they reveal how cultural factors contribute to moral action by constraining the individual self, although not all aspects of the non-self-model are supported. In Vietnam, the Buddhist non-self led to the negation of self-interest by means of compassion for other sentient beings, thus emphasizing social interdependence. In Taiwan, the social person was accentuated as a result of the influence of the Confucian relational self, role ethics, collectivism and family reverence. However, whereas these cultural influences were relatively automatic in Taiwan, the Buddhist non-self was more the result of an ongoing reflexive self-transformation process.

The study makes a number of contributions, both theoretical and practical. First in terms of theory, our study extends understanding of self since, in contrast to individualistic models, it uses underexplored notions of non-self and the relational self from Buddhism and Confucianism to show the importance of social influences. The findings provide support for the Mandala Model of the Self (Hwang, 2011) and also its extension into the non-self-model (Shiah, 2016) although with reservations. Second, we respond to the limited empirical studies examining moral action (De Los Reyes Jr, et al., 2017; DeTienne et al., 2019). Our empirical findings show how cultural impacts affect the way the model is activated in two different contexts. These theoretical contributions have important implications for practice and so lead to the paper's third, practical contribution, for example in areas such as corss-cultural management and communication. To these ends, we present two case studies offering evidence for social knowledge prompting moral action resulting from restraint of the individual and emphasis on the social person. We explore the mechanisms behind such moral action and so respond to the call for a more integrated and interdisciplinary approach by bringing in insights from the field of psychology (De Los Reyes Jr, et al., 2017; DeTienne et al., 2019).

This paper proceeds with a review of the relevant literature on relevant theories of the self and a brief introduction to the Buddhist non-self and the Confucian relational self. The methodology and findings from the two case studies in Vietnam and Taiwan are then presented before a general discussion and presentation of the conclusion.

\section{Models of the Self and Moral Action}

An understanding of the self is crucial to concepts of the formation of moral behaviours since it is argued that moral issues offer little knowledge about how or when a person actually behaves ethically (Blasi, 1980; DeTienne et al., 2019; Floyd et al., 2013). There have been a number of approaches to explore how people justify their decisions when faced with moral dilemmas and how they develop a sense of morality through cognitive development or psychological qualities (Kohlberg, 1969; Blasi, 1983; Piaget, 1932/1977; Rest, 1983). Kohlberg described stages of moral development, which he claimed as universal, based on the belief that morality is manifested within moral judgments that are shaped through stages of development (Kohlberg, 1971). However, Kohlberg's framework has been criticized for a number of reasons (e.g. DeTienne et al., 2019; Lapsley \& Hill, 2009). First, the ability to reason does not necessarily foretell whether people act morally (DeTienne et al., 2019) and so fails to address the moral judgementaction gap where individuals may understand what is moral but fail to act on that understanding (Hannah et al., 2020). Second, overemphasis on universalism goes against behaviourism (Lapsley \& Hill, 2009) and can underestimate the impacts of organizational and social norms (DeTienne et al., 2019), since environmental factors can strongly influence 
individuals' moral behaviours (Kilduff et al., 2016; Reynolds et al., 2010).

Blasi's model of the self (Blasi, 1983) moves away from universal concepts of morality and depicts the self as the mediator of moral reasoning and action to explain the moral judgement-action gap (Blasi, 1995). The three factors involved are the moral self (moral values defining self-identity), personal responsibility (determining action following moral judgement) and self-consistency (uniformity of judgement and action). Jennings et al. (2015) consider Blasi's model to be "foundational for moral self-theory" (2015, p. S104), prompting a surge of research which, however, has not been integrated into a holistic framework. They summarize current understanding as being based on the Aristotelian premise of morality being a personal characteristic with the moral self-consisting of a 'having' side and a 'doing' side. The former is cognitively and socially constructed (Bandura, 1991) by the "roles, practices, and interpersonal interactions within the social-moral context in which a person is embedded, such as family, community, or organization" (2015, p. S105). However, this social influence is relatively muted which is particularly problematic for societies where social influences are more important. In contrast, the impact of the social is much more explicit in the MMS which will now be described.

\section{Hwang's Mandala Model of the Self}

By giving more prominence to the socialized yet reflexive individual influenced by their cultural traditions, the model proposed by Hwang (2011) addresses the deficits of the models described above, reflecting the second contribution of this paper. Objecting strongly to the reductive binary research paradigms of individualism-collectivism (Hofstede, 1980) and the independent-interdependent self (Markus \& Kitayama, 1998), Hwang (2011) developed an alternative model influenced by indigenous psychology. He describes his model as universal, ontologically rooted in critical realism (Bhaskar, 1979) and epistemologically based on analytical dualism (Archer, 2003). In this concept of 'one mind, many mentalities' (Shweder et al., 1998), it is proposed that universal mechanisms of the self can be activated differently depending on social or cultural conditions, which is a crucial difference from the models reviewed above. Furthermore, the fallacy of conflation can be avoided by social structure, culture and agency being treated as analytically separable, even though they may not be separate entities (Fig. 1).

Hwang's model represents the self as the centre of socialized reflexive person whose experienced life world is represented by a circle within a square indicating objective reality. This self is in the middle of two bidirectional arrows, the horizontal arrow showing a relationship between 'wisdom/ knowledge' and 'action/ praxis' and the vertical arrow

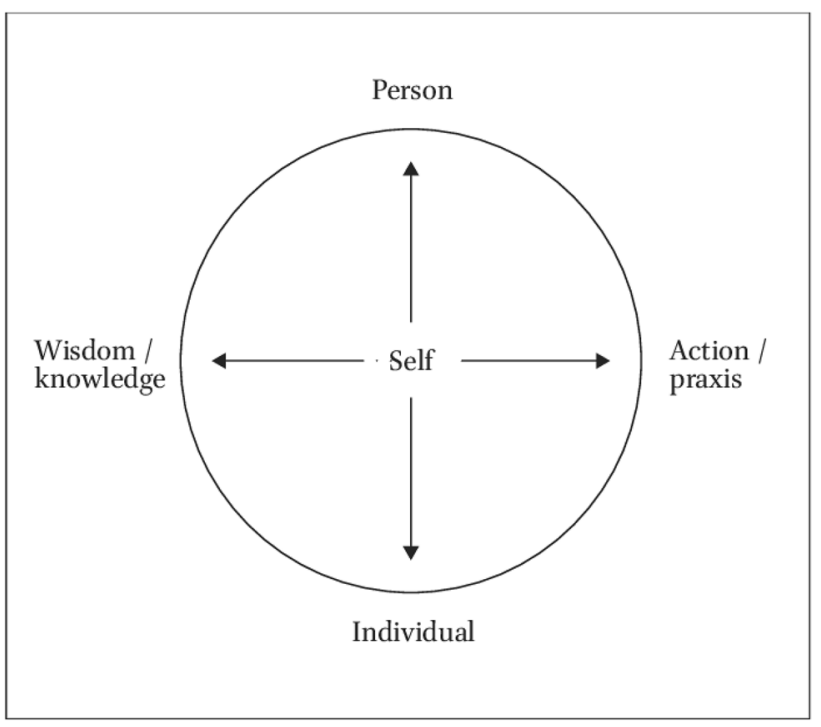

Fig. 1 The Mandala Model of the self (Hwang, 2011)

showing a relationship between 'person' and 'individual'. These four concepts are outside the circle but within the square, indicating the action on the self of forces from the lifeworld and all five concepts have special meanings in cultural psychology. 'Person' is a sociological concept, representing an agent-in-society socialized in a particular culture, together with its specific meanings, values and appropriate behaviours. In contrast, 'individual' is a biological concept with corresponding biological needs. 'Self' is a psychological concept, being the locus of experience capable of agency, knowledgeability and reflexivity (Giddens, 1984, 1993). When someone is prompted to act, they may do so as a socialized person and/ or a biological individual and they draw on their personal or social stock of knowledge, the latter of which is maintained by the cultural group or groups of which they are a part. Hwang defines cultural group very loosely as those who identify with a specific group and whose daily social practices form a tradition. "For example, Christianity in Europe, Confucianism in East Asia, Hinduism in South Asia, and Islam in the Middle-East and Southeast Asia, are significant cultural groups" (Hwang, 2011, p. 7). In this sense, Buddhists are also a cultural group with a particular social stock of knowledge, including for example, the four Nobel Truths, non-attachment, interdependence, emptiness and non-self as described below. In this way, the influence of the social is made more explicit, with the self being able to act as both a socialized person able to draw and reflect on social knowledge and as a biological individual with personal knowledge.

The MMS has been used to demonstrate aspects of the Confucian self (Wu, 2017), but more interestingly for current purposes, it has also been developed into a theory of the Buddhist non-self by Shiah (2016) (Fig. 2). 


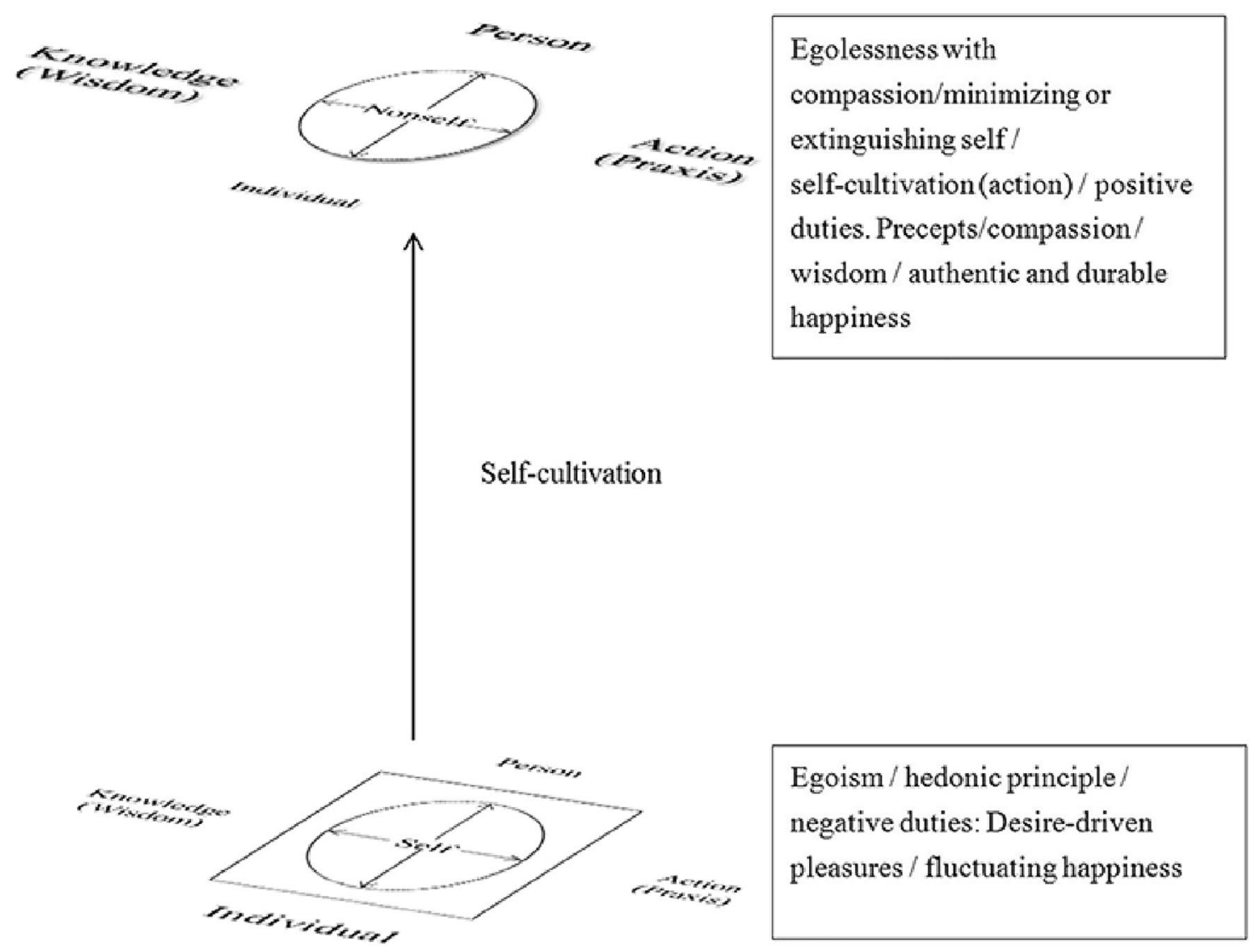

Fig. 2 Non-self-theory (Shiah, 2016)

There are three features which are of relevance here. First, non-self is achieved as a result of self-cultivation. Second, the outer square representing the external world is no longer there, signifying the emptiness of phenomena and the renunciation of worldly things. Third, the importance of the individual in the lower layer is emptied out in non-self so that it is the interdependence of the social person in the top layer which is emphasized. These are important facets of the Buddhist non-self which will now be considered in more detail before the model is revisited later in the paper.

\section{Engaged Buddhism and Non-self}

\section{Non-self: Reflexive, Processual and Transformational}

Non-self is achieved as a result of a process of transformative personal growth along a continuum with egoism, a desire-driven sense of self (Albahari, 2014), at one end and non-self at the other. This involves the reflexive accumulation of wisdom by learning from successes and failures (Vu et al., 2018) and recognition of the detrimental psychological effects of egoism based on biased self-interest and self-centeredness (Dambrun \& Ricard, 2011) through an understanding of the impermanent nature of the universe.

\section{Non-self: Empty and Interdependent}

The self cannot exist without its surroundings and even that existence is empty. Therefore, the notion of non-self reflects the principle of dependent arising, emphasizing the fact that nothing can stand alone, just like how the material mind is "embodied in a brain dependent on material causes and conditions" (Schuyler, 2012, p. 6), which is also highlighted in Shiah's (2016) interpretation of non-self. The notion of nonself in Buddhism is developed from the theory of emptiness in asserting that all phenomena exist in dependence on each other (Thurman, 2005). Emptiness implies fullness because each phenomenon is empty of an independent self (Van Gordon et al., 2016). The emptiness of phenomena does not refer to the exclusion of the external world as suggested by Shiah's (2016) interpretation, but rather an acknowledgement of its transiency and empty nature.

In this way, emptiness theory helps to explain why there is no self in a relational nature of the universe and how emptiness is form, and form is emptiness (Streng, 1967). Moving 
away from self-centredness within non-self facilitates the understanding of interconnectedness, which is crucial in contemporary management to identify complex systems dynamics so that necessary organizational changes can be adopted quickly (Metcalf \& Benn, 2012, 2013). Non-self is explained by the Buddhist assumption that, since each individual has five aggregates known as form, feelings, perceptions, formations and consciousness, "an inherently existing self may not be found within the aggregates whether in singular or in sum" because "the body manifests only in dependence on its constituent parts" (Shonin et al., 2014, p. 10). Therefore, the Buddhist doctrine of non-self rejects the isolated self in forms of self-centeredness and egocentricity (Magid, 2003). It is, however, important to clarify that the state of non-self or selflessness in Buddhist in "not a case of something that existed in the past becoming non-existent, rather, this sort of 'self' is something that never did exist. What is needed is to identify as non-existent something that always was non-existent" (Gyatso, 1984, p. 40).

Studies show that there are useful and practical Buddhist principles that can be applied to facilitate ethical approaches and promote ethical reasoning in managers and organizations (Marques, 2010, 2012; Pace, 2013; Vu, 2019; Vu \& Tran, 2019). For instance, Gould (1995) suggested the use of experiential meditative exercises to heighten awareness of the ethical implications of personal behaviours, while Marques (2010) highlighted both the advantages and disadvantages of Buddhist practices in contemporary working environments. Other Buddhist principles, such as karma, impermanence and non-self, have also been studied and applied in business ethics. Karma, the law of interdependent causation (Thondup, 1995) discourages people from engaging in negative acts that could harm others by encouraging them to consider the consequences of actions (Rinpoche, 1993) and so facilitates sustainable management approaches ( $\mathrm{Vu}$ $\&$ Tran, 2019). Impermanence refers to the perpetual state of change of all phenomena (Yoneyama, 2007), indicating a means of coping with attachment (Rinpoche, 1993), helping the realization of the empty nature of such attachment to material pursuits (Pace, 2013) and encouraging contextsensitive managerial approaches. Non-self, the ability to let go of the self and associated desires causing human suffering (Goleman, 2003), encourages the avoidance of self-serving pursuits that can result in unethical behaviour by promoting egoless managerial approaches (Vu \& Tran, 2019).

In this study, we further examine non-self in an engaged Buddhist context. In the scope of this study, we characterize engaged Buddhism not as activism towards social change (Cozort \& Shields, 2018) but as a process of sense making involving the application of Buddhist principles in organizational contexts (Main \& Lai, 2013). Many contemporary organizational issues arise from attachment to the self in non-relational forms. The Buddhist interpretation of the self can be explained by the level of attachment, which is shown by Western studies tending to place the self at the centre in comparison to all other life forms (Shonin et al., 2016). For instance, while promoting authenticity in organizations, ironically leaders may fantasize about their selves, leading to narcissism (Steyrer, 2002) which can trigger egocentric portrayal (Schwarz, 1990). A Buddhist interpretation of the self is, therefore, crucial to unpack complexities of how the notion of self does not exist in isolation but can be an object to the organization's subject, and how this subjectivity can be corrupted in the service of collectivity (Ford \& Harding, 2011).

In summary, the key features of the Buddhist non-self can be seen to be its emptiness, interdependence and reflexive and non-attached nature. The difference from the Confucian self will now become apparent as the literature on the Confucian relational self is reviewed.

\section{The Confucian Relational Self}

Confucian concepts of reciprocity, benevolence, sincerity, roles and harmony are also directly relevant to modern day business organizations (Romar, 2004b). Through self-regulation, a process of regulating one's character and behaviour through benevolence (ren), appropriateness ( $y i$ ), ritual propriety $(l i)$, wisdom $(z h i)$, trustworthiness $(x i n)$ and filial piety (xiao), Confucian principles "constitute the horizon of significance that makes our choices intelligible" (Sundararajan, 2005, p. 39). Thus, Confucianism can foster humanistic organizations by promoting moral behaviour rather than self-interest and material gain (Fan, 2002; Woods \& Lamond, 2011). Confucian ethics can help managers follow more ethical standards of practice in a way that facilitates the development of overall character and attitudes, rather than relying on conformity to written ethical codes. Furthermore, due to its emphasis on roles, collectivism, interpersonal relationships and harmony (Romar, 2004a), Confucian ethics also encourages moral action through personal responsibility and consistency of the self with social roles (Woods \& Lamond, 2011).

Confucians see the person as embedded in a particular social network and the boundary of the self may be extended to include significant others (Hwang, 2012). In this way, Confucianism places an emphasis on collectivism, with the cardinal concepts of ren-yi-li (compassion, appropriateness and propriety) (Hwang, 2012; Ip, 2009b; Zhu, 2015). These describe how the moral self is governed by benevolence and compassion towards others (ren), committed to the internal cultivation of ethical values such as humanity, justice, trustworthiness and persistence, rather than pursuing selfactualization and accentuating external inclinations ( $\mathrm{Yu}$, 2007). The focus is on a continuous process of development, 
where a virtuous character is deepened and perfected. This enables the person to become a junzi, an exemplary person (Ames, 2011), having not only a purposeful life constrained and directed by virtue but also with an essentially social nature, helping others in the pursuit of the virtues in order to achieve social harmony (Lin et al., 2013; Yu, 2007). In this way, Confucianism guides how the individual is constrained and the social person is encouraged through compassion (ren), with role-appropriate decisions ( $y i)$ resulting in moral action ( $l i)$.

This inhibits the tendency of individualism (Lin et al., 2013) and promotes collectivism and the interests of the group by placing communal interests above those of the individual. Both need to be aligned for harmony to be maintained and so individual well-being is only possible by means of the realization of the well-being of the group (Ip, 2009a). This Confucian concept of harmony has been described as the most cherished but undervalued concept in Chinese culture ( $\mathrm{Li}, 2006)$ and "achieving harmony is the most valuable function of observing propriety in our roles and relations (li)" (Analects 1:12). The achievement of harmony is a guiding standard in all things and applies to all levels of society, not only that of individuals but also those of the family, society and state (Chu \& Moore, 2020). It is encapsulated in the doctrine of the mean, which is "the universal basis of every harmony" (Sim, 2007, p. 103) where the goal is to maintain balance (Gardner, 2007). As such, the concept of harmony is all encompassing and the cardinal concepts of ren-yi-li again play a crucial role.

\section{Role Orientation and Family Reverence}

Confucianism, thus, emphasizes social relatedness and roles in its concept of the self-the 'relational self' -in the dimension of self-other demarcation and individual identity, and the Confucian individual is interpreted in connection with the community of which he or she is a part (Chan, 2008). Confucian individuals are expected to fulfil the obligations of their role in relationships, particularly to family members, and indeed should seek fulfilment from submitting to their role (Hamilton, 1990). This has been described by Ames and Rosemont (2011) as role ethics (lun li)_-"a specific vision of human beings as relational persons constituted by the roles they live rather than as individual selves" (p. 109). Rosemont (1988) even considered that these roles resulted in there being no autonomous self for early Confucians although this position has been criticized by some as being too extreme (for example Bellah, 2016). Nevertheless, roles are a central component of the Confucian self and the concept of ren is embedded within the wu lun (five relations) - relations between father and son, emperor and subject, husband and wife, elder brother and younger brother and between friends.
These five relations are largely familial in nature (Chan, 2008) and filial piety (xiao) or family reverence (Ames, 2011) is regarded as elemental among virtues of human relationships (Yao, 2000). These relationships are largely hierarchical and this hierarchical nature of social relations has always been considered as a part of traditional Chinese society (Hwang, 1987). However, whilst those in more dominant positions are not obliged to reciprocate in kind, they are constrained by the responsibilities of their role to act morally. If they do not, subordinates are required to remonstrate with them-“...remonstrance is the only response to immorality. How could simply obeying the command of one's father be deemed filial?" (Xiaojing 15). Such concepts are socially embedded and ethical standards are to be found in the societal rituals and codes of behaviour-a person's life is bounded by their relationships and the obligations of their consequent roles. Hamilton (1990) points out that the emphasis is on the subordinate's duty to obey (hsiao) and legitimate acts of power and obedience are restricted to behaviour within the role sets of wu lun.

In summary, Confucianism stresses the relational self with self-interest being constrained by the process of selfcultivation and ren-yi-li. Role ethics are emphasized and lead to a hierarchical social structure but with those in more dominant positions having clear responsibilities and obligations. Having reviewed the relevant literature, the methodology for our empirical data will now be presented.

\section{Methodology and Methods}

\section{Research Methods}

The theoretical perspective employed in this study is that of critical realism following Bhaskar (2008), since it supports the idea that individual's physical contexts have a causal influence on their beliefs and perspectives. A qualitative and inductive approach was adopted because it provides a deeper understanding of social phenomena (Silverman, 2013). Methodologically, given the novelty of the study context and the relative paucity of empirical studies in this area, an exploratory approach was adopted (Yin, 2018, p. 10) which employed a multiple case study method as "an empirical inquiry that investigates a contemporary phenomenon within its real-life context, especially when the boundaries between phenomenon and context are not clearly evident" (Yin, 2018, p. 18).

Case studies can prove to be invaluable in adding to understanding, extending experience and increasing conviction about a subject (Stake, 2000). They can be conducted for different purposes ranging from the presentation of individual studies to the attempt to arrive at broad generalizations without detailing the results of the individual 
Table 1 Participants' information

\begin{tabular}{|c|c|c|c|c|c|}
\hline Reference & Gender & Age & Position & Company & Sector \\
\hline VI1 & $\mathrm{F}$ & $36-45$ & Senior staff in Research \& Development & $\mathrm{VC} 1$ & Manufacture \\
\hline VI2 & M & $36-45$ & Project Manager & & \\
\hline VI3 & M & $24-35$ & Project Assistant & & \\
\hline VI4 & $\mathrm{F}$ & $36-45$ & Risk Manager & $\mathrm{VC} 2$ & Finance \& Banking \\
\hline VI5 & $\mathrm{F}$ & $36-45$ & Credit Manager & & \\
\hline VI6 & M & $24-35$ & Customer Service Staff & $\mathrm{VC} 3$ & \\
\hline VI7 & M & $36-45$ & Project Manager & & \\
\hline VI8 & M & $36-45$ & Digital Banking Supervisor & & \\
\hline VI9 & M & $36-45$ & Project Manager & VC4 & Construction \\
\hline VI10 & M & $46-60$ & Deputy Manager & & \\
\hline VI11 & $\mathrm{F}$ & $24-35$ & Architecture & VC5 & \\
\hline VI12 & M & $36-45$ & Quality and Assurance Manager & & \\
\hline VI13 & $\mathrm{F}$ & $24-35$ & Accountant & & \\
\hline VI14 & $\mathrm{F}$ & $46-60$ & $\mathrm{CEO}$ & VC6 & Education \\
\hline VI15 & $\mathrm{F}$ & $36-45$ & Lecturer & & \\
\hline VI16 & M & $46-60$ & Program Manager & & \\
\hline VI17 & $\mathrm{F}$ & $36-45$ & Branch Manager & VC7 & Pharmaceutical \\
\hline VI18 & $\mathrm{F}$ & $46-60$ & Managing Director & & \\
\hline VI19 & M & $36-45$ & Marketing Manager & & \\
\hline VI20 & $\mathrm{F}$ & $24-35$ & Product Representative & & \\
\hline VI21 & $\mathrm{F}$ & $24-35$ & Product Representative & & \\
\hline VI22 & $\mathrm{F}$ & $24-35$ & Customer Service Staff & VC8 & \\
\hline VI23 & M & $24-35$ & Sales & & \\
\hline VI24 & M & $46-60$ & Managing Director & VC9 & Telecommunication \\
\hline VI25 & $\mathrm{F}$ & $24-35$ & Project Assistant & & \\
\hline VI26 & $\mathrm{F}$ & $46-60$ & $\mathrm{CEO}$ & VC10 & Printing \& Publication \\
\hline VI27 & M & $24-35$ & Accountant & & \\
\hline VI28 & M & $24-35$ & Marketing Staff & & \\
\hline VI29 & M & $36-45$ & Managing Director & VC11 & Transportation \\
\hline VI30 & M & $36-45$ & Human Resource Manager & & \\
\hline VI31 & $\mathrm{F}$ & $24-35$ & Customer Service Staff & & \\
\hline TI1 & $\mathrm{F}$ & $46-55$ & Accountant & TC1 & Import/ Export \\
\hline TI2 & $\mathrm{F}$ & $26-35$ & Merchandiser \& Shipping Officer & & \\
\hline TI3 & M & $26-35$ & Merchandising \& New Market Development & & \\
\hline TI4 & $\mathrm{F}$ & $46-55$ & Founder & & \\
\hline TI5 & M & $36-45$ & Founder & $\mathrm{TC} 2$ & Advertising \\
\hline TI6 & $\mathrm{F}$ & $26-35$ & Accounting Manager & & \\
\hline TI7 & $\mathrm{F}$ & $16-25$ & Assistant Producer & & \\
\hline TI8 & M & $26-35$ & Online Merchandiser & TC3 & Retail \\
\hline TI9 & $\mathrm{F}$ & $26-35$ & Store Manager & & \\
\hline TI10 & M & $26-35$ & Shop Assistant & & \\
\hline TI11 & $\mathrm{F}$ & $36-45$ & Founder & & \\
\hline TI12 & $\mathrm{F}$ & $26-35$ & Store Manager & & \\
\hline TI13 & M & $36-45$ & Deputy General Manager & TC4 & Wholesale \\
\hline TI14 & M & $26-35$ & Sales & & \\
\hline TI15 & $\mathrm{F}$ & $26-35$ & Buyer \& Sales & & \\
\hline TI16 & M & $46-55$ & General Manager \& Founder & & \\
\hline TI17 & $\mathrm{F}$ & $26-35$ & Sales Assistant & & \\
\hline
\end{tabular}


Table 1 (continued)

\begin{tabular}{|c|c|c|c|c|c|}
\hline Reference & Gender & Age & Position & Company & Sector \\
\hline TI18 & M & $36-45$ & CEO \& Partner & TC5 & Marketing \\
\hline TI19 & M & $26-35$ & Film Producer & & \\
\hline TI20 & M & $26-35$ & Head Engineer & & \\
\hline TI21 & $\mathrm{F}$ & $26-35$ & Managing Director & & \\
\hline TI22 & $\mathrm{F}$ & $26-35$ & Chief Editor & & \\
\hline TI23 & M & $26-35$ & Web Page Design Director & & \\
\hline TI24 & $\mathrm{F}$ & $26-35$ & Assistant Marketing Manager & & \\
\hline TI25 & M & $26-35$ & Project Manager & & \\
\hline TI26 & M & $26-35$ & Sales \& Marketing Director & & \\
\hline TI27 & M & $36-45$ & Director of Engineering and Information Design & & \\
\hline TI28 & M & $46-55$ & Founder & TC6 & IT Training \\
\hline TI29 & $\mathrm{F}$ & $26-35$ & Sales & & \\
\hline TI30 & M & $26-35$ & Software Programmer & & \\
\hline TI31 & $\mathrm{F}$ & $26-35$ & Marketing & & \\
\hline TI32 & M & $36-45$ & President \& Founder & TC7 & HiTec \\
\hline TI33 & $\mathrm{F}$ & $36-45$ & Chief Financial Officer & & \\
\hline TI34 & M & $36-45$ & Founder & & \\
\hline TI35 & M & $26-35$ & Research \& Development Director & & \\
\hline
\end{tabular}

studies separately (Yin, 2018). This paper falls into the latter category since, although the original driver of the two case studies differed, they both had the broad objective of investigating how tradition influences society. Similarly, although the design of the two may have differed in the detail, it can be argued that these differences do not prevent the data collected being used for the purposes of this paper. Consequently, by way of a cross-cultural study, the authors are attempting to draw generalizable conclusions that could apply to other cultural studies (Crane, 1998).

The data for both case studies originally came from larger projects-investigating the roles of engaged Buddhism and Confucianism in SMEs in Vietnam and Taiwan respectively. However, a variety of different interesting themes emerged from both sets of data, including notions of the self in both traditions. It is acknowledged that both countries can be described as being high-context but this only emphasizes the value of empirical evidence from different environments. A summary of the interviewees, SMEs and industry sectors is shown in Table 1.

For Vietnam, participants of the study in 2016 were Buddhist practitioners with more than 5 years' experience of practicing Buddhism and so able to demonstrate how their specific applications of Buddhist principles have influenced the studied SMEs. The initial interviewees were identified based on initial acquaintances in the Buddhist practitioners club following the Vajrayana tradition, where Buddhist businesswomen and businessmen gather to share experiences and challenges in practicing Buddhism in business contexts. Subsequently a snowball technique was used and this resulted in a total number of 31 interviewees from 11 SMEs from eight different sectors in Hanoi. These SMEs were non-state organizations, where more freedom and opportunities are available to initiate and apply Buddhist concepts. For instance, a private higher educational organization was examined among other organizations in the service sector (e.g. finance and banking) because, compared to state-owned educational systems, private systems allow greater flexibility, encourage active approaches and innovative curriculum design, where ideas are not restricted by hierarchical and bureaucratic systems. The interviews generally lasted 45-60 min and were conducted, recorded and then transcribed in Vietnamese for analysis. Back translation-into English and then back into Vietnamese-was carried out to make sure that the original meaning of the text was not lost or distorted during translation.

The original primary data collection in Taiwan took place in 2014, involving 39 interviewees in seven SMEs from seven sectors, with the companies again being selected using a snowball technique following initial personal contacts. Each interview took 60-90 min and was conducted and transcribed in Mandarin Chinese before being translated into English. In contrast to the Vietnamese study, no questions referred to Confucianism either directly or indirectly. 
However, as in Vietnam, the large volume of data collected provided ample material to be used for other research purposes such as that being investigated here. The data was corroborated for the purposes of this paper in 2018 and subsequently 35 interviews with staff at all levels of seven SMEs were judged to still be valid, the remaining four people being uncontactable.

The quotes below are identified by the country and interviewee, e.g. VIx for interviewees from Vietnam and TIx for interviewees from Taiwan. For both studies, the transcriptions were imported into NVivo as a tool for organizing and analysing the data. Thematic analysis was adopted, which entails searching for important themes in the research phenomenon (Daly et al., 1997). It involves a systematic coding and categorizing approach to explore the textual information to identify trends, patterns of words used, their frequency, relationships, structures and discourses in communication (Grbich, 2012; Mayring, 2000; Pope et al., 2006). The initial concepts were identified through open coding, since it was better suited to the discovery of topics running through the interviews which could be grouped into underlying themes (Gray, 2009). Then axial coding was used to look for relationships among first-order concepts in order to gather them into second-order themes. Finally, similar themes were linked to overarching dimensions and so an emerging framework was assembled.

As highlighted by the different sample characteristics and interview questions aiming at exploring specific Confucian and Buddhist embedded values in SMEs in Taiwan and Vietnam, the intention was not to seek equivalences between comparative settings but to generate phenomena of interest through exploratory study for further followup studies. Having reviewed the research methodology, background information forming the context of the case studies will now be presented.

\section{The Context of the Case Studies}

\section{Vietnam and Buddhism}

Buddhism has existed in Vietnam for over 2000 years and is now the dominant ideology, affecting cultural, economic, religious and political life. Coming to Vietnam by way of China and India, Vietnamese Buddhism was initially heavily influenced by China, reflecting a mixture of Taoism, Confucianism, ancestor worship and local deities which coexisted until the periods of French and American colonialism (Ta, 1989; Topmiller, 2000). Confucianism was preferred by the ruling officials for a period from the fifteenth to eighteenth centuries and was especially influential in the area of the family. Subsequently under communism, Vietnam's ideology appeared to many to be corrupted and misguided. This prompted calls for the preservation of traditional cultural values (Kleinen, 1999; Luong, 1993; Malarney, 2003), spiritual reassurance (Taylor, 2004) and the restoration of practices such as prayer, ritual and offerings (Riesebrodt, 2007). More recently in the twenty-first century, Confucianism has been viewed as causing backwardness and superstition (Leshkowich, 2006), compared to the Buddhist principles of flexibility and freedom. Consequently, although Confucianism is still influential, Buddhism has become increasingly important in the Vietnamese life (Nguyen, 2009) which has witnessed the rise of a spiritual movement with engaged Buddhism as part of the country's contemporary transition (Vu \& Gill, 2018). This movement has been rapidly influencing SMEs in Vietnam, which make up nearly $98 \%$ of all enterprises (Pham \& Nguyen, 2017), and is especially the case in the private sector where company owners have more flexibility and freedom to introduce new initiatives.

\section{Taiwan and Confucianism}

Taiwan's history of preserving its Confucian heritage started with initial large-scale migration from mainland China around 400 years ago and continued throughout the Japanese occupation (1895-1945). Its further promotion after the advent of democracy in 1986 means that Taiwan can still be considered to be heavily influenced by Confucianism with a consequent emphasis on relations within society, role orientation and collectivism (Whitley, 1999). It also leads to paternalism and stabilization of the economic system at the level of the family business enterprise (Beattie, 1979; Hall, 1988; Mann, 1987). Combined with other factors, such as equal inheritance, strong preference for self-employment and state domination of large-scale commercial activities during the period of rapid economic growth in the 1960s, the Taiwanese economy developed into what has been described as familial capitalism based on SMEs (Gerlach, 1992 ) with $78 \%$ of the total workforce working for SMEs (SME Administration Taiwan, 2019) compared with 58\% in OECD countries (OECD, 2017). SME employers commonly apply a paternalistic management style rooted in Confucian values, resulting in a harmonious atmosphere with employer authority stemming from their leadership position rather than competence (Chen et al., 2003). Furthermore, the institutional logics of Confucianism, the family and SMEs have been found to often reinforce each other to stabilize a familial atmosphere within the workplace (Chu \& Moore, 2020).

Having described the research methods employed and the background contexts of the case studies, the findings will now be presented. 


\section{Findings}

In this section, we show how engaged Buddhism and Confucianism provide mechanisms that promote moral action by emphasizing the social person instead of the individual and the consequent salience of social knowledge.

\section{Vietnam}

The notion of non-self is one of the core aspects of Buddhism, involving a process of self-transformation that requires personal efforts and observations to actively respond to external conditions rather than relying on external changes on their own. According to participants, non-self involves the development of mechanisms facilitating selfregulation for ethical actions in a number of ways.

\section{De-emphasizing the Individual Through Self-decentralization and Social Interdependence}

Interviewees stated that the practice of attaining non-selfreferring to the application of their understanding of nonself to deconstruct and consider motives and actions in daily life-helped them to reconsider and abandon egocentric pursuits to do with the individual:

My experience is that the more I think about my self and the need to fulfil that self, the more I suffer. I become stressed to think about what others think about me, to wait for my expectations to be fulfilled... With non-self, I realized that I do not become more moral or more respectful by keeping trying to prove it ... morality comes from the rejection of my own ego first. (VI12)

Interviewees shared that the letting go of individual concerns emphasized by non-self promoted moral values:

I am more aware of moral issues and consequences since I have been trying to practice non-self. I used to ignore my colleagues' wrongdoings because I was afraid that speaking out would affect myself and my relationships with other colleagues as they may see me as being noisy or hostile to them. However, I came to realize that such thinking was all about myself and not about how it jeopardizes the company when immoral behaviours are tolerated by others. (VI21)

These findings show that non-self involves a process of decentring the individualistic self that enables individuals to pay more attention to the needs of others rather than themselves. This helps them to develop more prosocial behaviours such as developing relationships with stakeholders
(Waddock, 2001) by being more morally responsive to others' needs.

Furthermore, the findings suggest that the practice of attaining non-self fosters interdependence, awareness of others and social responsibilities rather than just those to the individual self.

Non-self has been an effective practice for me to take into consideration stakeholders' expectations and social initiatives rather than just thinking about my own career development. (VI2)

The practice of non-self has changed me. I have become more attentive and more responsible, which is very important for me as a risk management analyst. (VI7)

Interviewees considered how they had become more aware of the interdependent nature of the social person rather than being centred on their own individualistic needs.

Non-self for me is the ability to think less about myself and more about others, including my family, my coworkers, my employees, my customers and others in society. It is a practice through which I have learnt to put my family's needs and my firm's needs above my personal needs. It sometimes even involves the sacrifice of my values. For instance, to get an urgently needed visa to import one of our pharmaceutical products which had a long list of patients waiting for it, I agreed to pay transactional costs to various gatekeepers to push the process faster. But this is not something I would do on a regular basis. (VI18)

All the above quotes demonstrate how the Buddhist nonself lessens the influence of the individual and promotes the social person.

\section{Moral Action from Reflexivity}

The need for ongoing reflexivity about the context of moral issues, organizational and social norms was highlighted by interviewees.

What you consider as moral actions are not necessarily what others believe. I was so proud when our firm could build a school to support local communities in a rural area. What I did not know was that some farmers were pressured by the local authorities to sell their lands at a cheap price for the school, which made them lose a sustainable way of earning for their living and making our firms' and local governments' intentions morally questionable. (VI11)

Some interviewees reaffirmed that the practice of attaining non-self remains challenging, requiring constant reflexivity in a process of self-transformation. There were 
concerns for the practicality of this practice due to contextual constraints.

Non-self is a practice that involves a learning process with it. You learn bits and bits every day and, eventually, you learn to evolve. I call it self-transformation and I would say that it comes with a package of painful experiences and lessons. For instance, I could not have fully understood the real meaning of non-self if it had not been for my stubbornness that cost an entire project and the jobs of two of my team members six years ago. It took me a long journey to be able to truly and reflexively judge my actions and learn from them. (VI17)

However, according to most interviewees, the practice of achieving non-self can be strengthened by consideration of karmic consequences to facilitate reflexive context-sensitivity and revise what is considered as moral actions and motives.

In general, in practicing Buddhism, you have to be skilful. It applies to the practice of non-self as well and it is extremely useful in our transitional context today. My actions are based on my motives, intentions, actions and outcomes. If bribing helps to save lives then I consider it a moral action as I am sacrificing my values to save people. My motives, intentions and outcomes reflect positive karma and my actions support those motives even though they can reflect negative karma. I am not saying my actions are justified. I am aware that such actions can cultivate negative karma, which I am prepared to take responsibility for in exchange for the benefit of others. (VI18)

The negotiation considers the karmic consequences involved, for oneself and for others, as well as both individual and collective karma (Garfield et al., 2015). Interviewees subsequently judged their actions against moral standards of motives, intentions and outcomes. A senior practitioner with nearly 20 years of Buddhist practice and experience as the $\mathrm{CEO}$ of an education organization suggested that:

For me, non-self can only be attained when you show total detachment from both your self and other selves to practice the right intention, right view and right livelihood. Any form of non-self that raises concerns about right and wrong for me is a misinterpretation of non-self. (VI14)

Following Buddhist emptiness theory, the above interviewee rejected clinging onto the self or onto others' expectations to shape a certain form of self. Incorporating non-self with the principles of the Noble Eightfold Path, self-regulation to foster ethical responses involves a process of self-judgement through reflexive self-transformation where individuals move away from individualistic and ego centric viewpoints to nurture the relational self within the 'right livelihood' by sacrificing the individual self.

These interviewees demonstrated that moral action resulted from them using social rather individual knowledge since Buddhist concepts such as right intention, right view and right livelihood became more salient for them. Similarly, non-self resulted in them focusing on social interdependence rather than their individual desires.

\section{Taiwan}

In Taiwan, the interviewees described how Confucian concepts shaped their moral selves and showed a strong orientation reflecting the Chinese saying "sacrifice the small self in order to achieve the big self", meaning that personal interest should subordinated to the common good (Busiol, 2016; Pye, 1992). They also emphasized the importance of roles for personal responsibility and that of harmony for self-consistency.

\section{Emphasizing the Social Person via the Relational Self}

It was clear from the interviews that the characteristics of the social person were promoted by an emphasis on social relations and the relational self. It was recognized that selfrestraint was needed in order to subordinate individual wishes:

To be a decent person, I think if you are willing to fulfil your responsibilities and your roles, if you are willing to control yourself and be responsible, then I think it is good. Not everyone is willing to control themselves. (TI5)

Such constraint of the individual self was reflected in an explicit sense of collectivism:

You see, people in our generation care about collectivism and tend to have the honour of the collective. We emphasize teamwork and team prestige. (TI5)

For the following respondent, social relations were underpinned by a sense of compassion for others (ren):

...when we select managers, they must have the quality to care for people, the empathy, the benevolence to deal with others and influence them, not by ordering them to listen... After all, if you have good relationships and good connections with others, then you make yourself have a feeling of affinity with them. (TI32)

These examples show the importance of the relational self, where the relations with and respect for others are paramount. 
These social relations were structured into roles which were recognized as having responsibilities to others which had to be fulfilled as demonstrated by the following quote:

It is about the relationships with different people. Confucianism sets a kind of standard. You should have a proper attitude towards a person according to your relationship with them. This is my opinion on Confucianism.... How are these relations reflected in this company? It is like this... As an employer, I take care of them instead of using them as a tool. I take care of my staff in earnest. (TI16)

This explicit importance of roles and responsibilities was also mirrored by the fact that, in the context of the SMEs in the study, it was not uncommon for the organization to be viewed as a family (Chu \& Moore, 2020):

The most important point of lun li (role ethics) in the workplace is respect and care for others, I believe... because the company is more like a big family. (TI26)

This facilitated the wider application of the concept of filial piety, together with the corresponding duties and responsibilities, applying beyond the family and within the organization:

We certainly defer to the idea of filial piety from our parents to our senior staff and supervisors in the office. I have never thought about this before but, now that we're talking about it, I realize that we don't think about it, we just do it as a habit. There is a Chinese saying-'older brothers be friendly, younger brothers be reverent, fathers show affectionate love and sons show filial piety and respect'. We are like a family in this company. I see my supervisor and the owner like my elder sisters, aunts. I don't only respect them but feel a certain affection towards to them. (TI10)

This example shows how the concept of filial piety was so deeply ingrained that people did not consciously think about it when acting, reflecting the deep-seated nature of Confucianism within Taiwanese culture. There was also evidence that the interviewees were aware that their decisions could lead to different outcomes with different implications for how they are seen, both by themselves and by others. It was important that the choices made were not viewed as socially incorrect:

I want to do the right things. I could make NT $\$ 50$ million immediately if I do a certain thing, but it is short term...it might be difficult for me next year and I may have to clean up the mess next year. I may lose some of 
my principles in this industry... You have to make your choice, but if you ask me, I would sacrifice revenue, so that I can face my colleagues and people in this field proudly...I have to consider what other people think of me. (TI13)

Although the interviewee above could have gained prestige by exceeding financial targets, this would have been at the expense of sacrificing some moral principles. They felt that it was more important to at in a way judged to be socially correct and so maintain their status in social relationships than be ashamed to face others. This notion of acting correctly also extended to helping others in both the short-term and the long-term as reflected in recognition from others in the industry:

For myself, the short-term definition of being successful is how to work with the team, but not to lead the team, and to achieve the corporate target. The longterm perspective is if I can help and support my teammates to achieve their career goals in a part of their lives. This is my main motivation-the reputation you make for yourself in this field, the people who used to work with you can be top managers in this field. I believe that it is the people who work with me in the team who have made me successful. (TI18)

In summary, the main area of similarity between the two studies was that both involved a degree of constraint of the individual in favour of the social person as exemplified by the notion of sacrifice of the small self to achieve the big self. In Vietnam, the Buddhist non-self led to the negotiation of self-interest by means of compassion for other sentient beings whereas in Taiwan, the Confucian relational self entailed constraint of individual self-interest by the considerations of role and ren-yi-li. On the other hand, the main areas of difference found were that the Buddhist non-self emphasized non-attachment whereas the Confucian relational self stressed collectivism. Buddhist practice involved an active but difficult process of reflection to recognize and act against addiction to egocentric desires, including those that might at first sight seem to stem from altruistic purposes or trying to fit in with others. In contrast, the culture of Confucian role ethics meant that a person's social roles took priority over the interests of the individual. Nevertheless, these differences all facilitate the notion of favouring the social person as opposed to the individual either by decentring from egocentric desires or by appreciating the ethical angles of collectivism and others.

\section{Discussion}

In exploring how the relational self in Confucianism and non-self in Buddhism facilitate self-regulation, our findings support the mechanisms suggested by the Mandala Model of the Self that promote moral action (see Table 2).

This regulation of the self involves the constraint of the individual to foster the social person. Based on our findings, in Vietnam the practice of attaining non-self facilitated selfdecentralization, the letting go of ego-serving pursuits and desires that encourage narcissism and obsession with desired end states of human needs (Lacan, 1977). Controlling the self, in the knowledge that self-interest can cause suffering and jeopardize the communal good, is therefore important, especially in contemporary contexts where embracing materialism may lead to unethical behaviours (Huang et al., 2012; Lu \& Lu, 2010). In Taiwan, Confucian values such as the relational self and collectivism also facilitate selfdecentralization by stressing the need for compassion and benevolence towards others with the concepts of ren-yi-li constraining self-interest.

In addition, to cultivate moral action from knowledge, reflexivity using social knowledge is crucial. In both studied contexts, social consideration for others reflected an emphasis on otherness rather than on the individual. Our findings in Vietnam show that Buddhist detachment facilitates reflexivity using social knowledge, in this case the fundamental assumptions underlying phenomena based on the Four Noble Truths, which then reduces attachment to individual or even corporate expectations that may not represent true ethicality. As suggested by Jensen and Wygant (1990) in developing self-valuing theory, in situations where normal rules do not apply employees need to have a sense of what is right without being bound by personal judgement or corporate policy. The ethical guidelines of the Noble Eightfold Path promote moral action based on principles such as right livelihood, right intention or right action as highlighted by our Buddhist interviewees. Our interviewees expressed how they learnt to be more socially responsible for others by nurturing the non-self rather than emphasizing self-serving expectations. The importance of moral action was also highly influenced by the understanding of the theory of karma by Buddhist participants. This involved consideration of motives, intentions, actions and outcomes to promote positive collective karmic outcomes, sometimes resulting in the sacrifice of personal moral values, relying on continuous reflexivity and total detachment from self-interest. In our case studies, this scenario was clearly demonstrated by a respondent in the pharmaceutical industry considering the need of patients above the payment of a bribe to gatekeepers. In other words, from our Buddhist viewpoint, mechanisms of 
ongoing reflexivity were crucial for social knowledge to be used to achieve ethical actions.

Mechanisms fostering social knowledge to promote moral action were also found in Taiwan. The centrality of Confucian role ethics and the importance of social relations stated by the interviewees led explicitly to individuals being aware of their responsibility to fulfil their duties and the mutual expectations of their social roles. This is underpinned by the linkage between compassion, decision making and action as expressed in the cardinal concepts of ren-yi-li, as well as those of family reverence. Also important were the Confucian concepts of balance and harmony, applied not just to the individual but also to the family, society and the state. Role ethics inform the status, obligations and duties of individuals so that goals are aligned and the concepts of ren-yi-li guide people to moral action. The automatic nature of how some interviewees acted according to the concept of filial piety demonstrates how ingrained these factors are and is indeed evidence for the importance of social norms and knowledge as opposed to individual moral reasoning or the reflexivity found in Buddhist participants. The resulting collectivism of the relational self constrains the individual and is characterized by social networks (Hofstede \& Bond, 1988), the prioritization of group interests (Chu \& Moore, 2020) and adherence to the ethical norms of society (Zhu, 2015). It has been found to affect ethical decision making more than any other cultural dimension (Husted \& Allen, 2008) and empirical studies show that managers with a higher sense of collectivism appear to be more ethical (Paul et al., 2006). Together, these concepts of social relations, role ethics and collectivism result in individuals fulfilling their mutual obligations and translating social knowledge into moral actions.

The high-context cultures of the two studies contexts demonstrate the importance of social norms that increase the salience of social knowledge leading to moral action. However, differences were evident in the enactment of nonself compared to the relational self since non-self requires ongoing reflexive negotiation between intentions, motives against others and context, whereas for the relational self, individuals are intuitively guided more by social values than reflexive analysis. This difference is demonstrated by the non-self-theory proposed by Shiah (2016), where this ongoing process of self-cultivation is emphasized as being necessary to reduce the influence of the external world and promote the social person. However, the resulting model as shown in Fig. 2 can be criticized in that the removal of the square representing the outside world conflicts somewhat with concepts of dependent arising and the interdependent nature of all things. Nevertheless, it is useful in showing how the reduction in importance of the individual in favour of the social person, which is not restricted to the Buddhist non-self as demonstrated by the Confucian relational self, is a mechanism for promoting moral action.
In summary, our findings provide support for and extend Hwang's Mandala Model of the Self by demonstrating how Buddhist and Confucian elements result in moral action. In Buddhism, the social person is facilitated by the non-self acting to decentralize egocentric desires. The salience of social knowledge is activated by the Nobel Eightfold path and moral action is encouraged by reflexivity and the theory of karma. In Confucianism, the relational self and collectivism promote the social person over the individual whilst role ethics, ren-yi-li and harmony result in social knowledge causing moral action.

\section{Conclusion}

Our paper makes a number of contributions, both theoretical and practical. First, in terms of theory, we have extended understanding of the self since a majority of models of the self underemphasise the importance of social influences. We have shown that the self is a multi-dimensional and dynamic construct influenced by agency and culture rather than a singular one solely based on individualism. The mechanisms described provide support for the Mandala Model of the Self (Hwang, 2011); both the Buddhist non-self and the Confucian relational self emphasize the social person over the individual, increasing the salience of social knowledge and demonstrating how a focus on otherness and social context are crucial for moral action. Furthermore, a number of influential sociological concepts are based on concepts of the self-for example Hofstede's cultural dimensions theory (Franke et al., 1991; Hofstede, 1980; Hofstede \& Bond, 1988), Hall and Hall's low- and high-context cultures (Hall \& Hall, 1990), Schwartz's theory of human values (Schwartz, 1992, 1994) and Maslow's influential hierarchy of needs (Maslow, 1943, 1954). These concepts all benefit from a secure foundation of an explicit and rooted theory of the self and self-regulation such as that provided by this paper. For example, Maslow's model concentrates of the needs of the individual and self-actualization and underemphasizes the role of social factors.

Second, we also respond to the limited empirical studies examining moral action (De Los Reyes Jr, et al., 2017; DeTienne et al., 2019) with empirical evidence from two case studies in two different contexts. Our findings illustrate how the underlying mechanisms of the self are activated in the two different Eastern traditions of Buddhist non-self and the Confucian relational self, shaping the process of self-regulation promoting moral action. The differing social contexts produce different types of social knowledge and show the importance of contextualization. Consequently, although both of the Eastern interpretations of the self reveal a more collective and moral viewpoint, the findings also 
show distinctions and different tensions associated with how individuals express their self in different cultures.

Third, our paper also makes important practical contributions. An understanding of the self informed by the impact of social influences has far-reaching practical implications in many areas, such as cross-cultural studies, international business and organizational studies. For example, processes concerning ethical codes of conduct, especially within multinational enterprises, (Logsdon \& Wood, 2005) should be informed by theories of the self. Cross-cultural communication (Meyer, 2014) can benefit from such concepts of the self and self-regulation as can cross-cultural management. Furthermore, there are also important practical implications for aspects of corporate legitimacy and how it is perceived by individuals (Palazzo \& Scherer, 2006; Suddaby et al., 2017). Conceptions of the self from different non-Western perspectives also have implications for practices such as decolonization and promotion of equality, diversity and inclusion. With a basis on Hwang's model, which has a justifiable claim to universality since it allows for cultural influences to be taken into account, such areas have a far sounder basis on which to base their practical proposals.

Our study is not without limitations. Our study focused on subjective experiences of the self, which can be prescriptive and descriptive on their own, and there may be limited independent perspective to validate or challenge such subjective determinations (Michaelson, 2019). We also acknowledge limitations in our sample size, which may hinder other alternative views of the self. Future studies may look into a larger sample size covering various provinces in both contexts.

However, it is not the purpose of this paper to present an exhaustive coverage of these issues but rather to point to the possibilities opened up by such a consideration and suggest areas of future research. The intention of this paper has been to show how the Confucian relational self and Buddhist nonself demonstrate how people regulate and constrain their selves toward moral action. This opens up the possibility, not only of several promising areas of future research, but also that consolidating evidence of these implications from different academic disciplines could arguably lead to further insights. For instance, beyond the well-established literature on psychological mechanisms affecting self-regulation, examining broader social contexts can shed light on how institutional, social, cultural aspects and changes contribute to the way individuals regulate their selves and perceive morality on that basis. We also encourage the exploration of the self from other spiritual and cultural perspectives, especially examining cross-cultural perspectives on selfregulation that may reveal cross-cultural and context-sensitive managerial approaches developing self-regulation towards ethicality, given that ethics is a relative term, interpreted dynamically in different contexts. We also note the possibility of future research by way of longitudinal studies into how concepts of the self change over time, prompted by the perceived increase in individualism described in our findings (Ralston, 2008).

Consequently, the contribution of this paper has been not only to present evidence, empirical and theoretical, for the existence of these other selves, but also to shed light on the implications for ethical behaviour. Although this may only be a thin beam of light into a dark room at present, it is hoped that the broad light of more exposure can lead to more general illumination.

Funding This study received no funding.

\section{Declarations}

Conflict of interest The authors declare no conflicts of interest.

Ethical Approval All procedures performed in the study involving human participants were in accordance with the ethical standards of the institutional research committee, and with the 1964 Helsinki declaration and its later amendments or comparable ethical standards.

Informed Consent Informed consent was obtained from all individual participants involved in the study.

Open Access This article is licensed under a Creative Commons Attribution 4.0 International License, which permits use, sharing, adaptation, distribution and reproduction in any medium or format, as long as you give appropriate credit to the original author(s) and the source, provide a link to the Creative Commons licence, and indicate if changes were made. The images or other third party material in this article are included in the article's Creative Commons licence, unless indicated otherwise in a credit line to the material. If material is not included in the article's Creative Commons licence and your intended use is not permitted by statutory regulation or exceeds the permitted use, you will need to obtain permission directly from the copyright holder. To view a copy of this licence, visit http://creativecommons.org/licenses/by/4.0/.

\section{References}

Albahari, M. (2014). Insight knowledge of no self in Buddhism: An epistemic analysis. Michigan Publishing, University of Michigan Library.

Alvesson, M., \& Robertson, M. (2016). Money matters: Teflonic identity manoeuvring in the investment banking sector. Organization Studies, 37(1), 7-34.

Ames, R. T. (2011). Confucian role ethics: A vocabulary. Chinese University Press.

Ames, R. T., \& Rosemont, H. (2011). Were the early Confucians virtuous? In C.-c. Huang (Ed.), Confucian role ethics: A vocabulary (pp. 109-130). National Taiwan University Press.

Aquino, K., Freeman, D., Reed, I., Lim, V. K., \& Felps, W. (2009). Testing a social-cognitive model of moral behavior: The interactive influence of situations and moral identity centrality. Journal of Personality and Social Psychology, 97(1), 123.

Archer, M. S. (2003). Structure, agency and the internal conversation. Cambridge University Press. 
Bandura, A. (1991). Social cognitive theory of self-regulation. Organizational Behavior and Human Decision Processes, 50(2), 248-287.

Bazerman, M. H., \& Sezer, O. (2016). Bounded awareness: Implications for ethical decision making. Organizational Behavior and Human Decision Processes, 136, 95-105.

Beattie, H. J. (1979). Land and lineage in China: A study T'ungCh'eng, Anhui, in the Ming and Ching dynasties. Cambridge University Press.

Bellah, R. (2016). Can we imagine a global civil religion? In P. J. Ivanhoe, \& S. Kim (Eds.), Confucianism, a habit of the heart: Bellah, civil religion, and East Asia. SUNY Press.

Bhaskar, R. (1979). The possibility of naturalism. Routledge.

Bhaskar, R. (2008). A realist theory of science. Routledge.

Blasi, A. (1980). Bridging moral cognition and moral action: A critical review of the literature. Psychological Bulletin, 88(1), 1.

Blasi, A. (1983). Moral cognition and moral action: A theoretical perspective. Developmental Review, 3(2), 178-210.

Blasi, A. (1995). Moral understanding and the moral personality: The process of moral integration. In W. M. Kurtines, \& J. L. Gewirtz (Eds.), Moral development (pp. 229-253). Allyn.

Brown, A. D. (2019). Identities in organization studies. Organization Studies, 40(1), 7-22.

Brubaker, R. (1984). The limits of rationality: An essay on the social and moral thought of Max Weber. Routledge.

Busiol, D. (2016). Psychoanalysis in Hong Kong: The absent, the present, and the reinvented. Routledge.

Chan, G. (2008). The relevance and value of Confucianism in contemporary business ethics. Journal of Business Ethics, 77(3), 347-360.

Chen, S., Ko, J., \& Lawler, J. (2003). Changing patterns of industrial relations in Taiwan. Industrial Relations: A Journal of Economy and Society, 42(3), 315-340.

Chu, I., \& Moore, G. (2020). From harmony to conflict: MacIntyrean virtue ethics in a Confucian tradition. Journal of Business Ethics, 165, 221-239. https://doi.org/10.1007/s10551-019-04305-6.

Cozort, D., \& Shields, J. M. (2018). The Oxford handbook of Buddhist ethics. Oxford University Press.

Crane, J. (1998). Social programs that work. Russell Sage Foundation.

Crockett, C. (2005). Grounding the theory of virtue. Unpublished $\mathrm{PhD}$ thesis, Robert Gordon University, Aberdeen, UK.

Daly, J., Kellehear, A., \& Gliksman, M. (1997). The public health researcher: A methodological approach. Oxford University Press.

Dambrun, M., \& Ricard, M. (2011). Self-centeredness and selflessness: A theory of self-based psychological functioning and its consequences for happiness. Review of General Psychology, $15(2), 138$.

De Los Reyes Jr, G., Kim, T. W., \& Weaver, G. R. (2017). Teaching ethics in business schools: A conversation on disciplinary differences, academic provincialism, and the case for integrated pedagogy. Academy of Management Learning \& Education, 16(2), 314-336.

DeTienne, K. B., Ellertson, C. F., Ingerson, M.-C., \& Dudley, W. R. (2019). Moral development in business ethics: An examination and critique. Journal of Business Ethics. https://doi.org/10.1007/ s10551-019-04351-0.

Driver, M. (2005). From empty speech to full speech? Reconceptualizing spirituality in organizations based on a psychoanalyticallygrounded understanding of the self. Human Relations, 58(9), $1091-1110$.

Fan, Y. (2002). Ganxi's consequences: Personal gains at social cost. Journal of Business Ethics, 38(4), 371-380.
Floyd, L. A., Xu, F., Atkins, R., \& Caldwell, C. (2013). Ethical outcomes and business ethics: Toward improving business ethics education. Journal of Business Ethics, 117(4), 753-776.

Ford, J., \& Harding, N. (2011). The impossibility of the 'true self' of authentic leadership. Leadership, 7(4), 463-479

Franke, H. F., Hofstede, G., \& Bond, M. H. (1991). Cultural roots of economic performance: A research note. Strategic Management Journal, 12, 165-173.

Gardner, D. K. (2007). The four books: The basic teachings of the later Confucian tradition. Hackett Publishing.

Garfield, J. L., Nichols, S., Rai, A. K., \& Strohminger, N. (2015). Ego, egoism and the impact of religion on ethical experience: What a paradoxical consequence of Buddhist culture tells us about moral psychology. The Journal of Ethics, 19(3-4), 293-304.

Gerlach, M. L. (1992). Alliance capitalism: The social organization of Japanese business. University of California Press.

Giddens, A. (1984). The constitution of society: Outline of the theory of structuration. University of California Press.

Giddens, A. (1993). New rules of sociological method: A positive critique of interpretative sociologies (2nd ed.). Stanford University Press.

Goleman, D. (2003). Healing emotions: Conversations with the Dalai Lama on mindfulness, emotions, and health. Shambhala Publications.

Gould, S. J. (1995). The Buddhist perspective on business ethics: Experiential exercises for exploration and practice. Journal of Business Ethics, 14(1), 63-70.

Gray, D. E. (2009). Doing research in the real world. Sage Publications Limited.

Grbich, C. (2012). Qualitative data analysis: An introduction. Sage Publications Limited.

Gyatso, T. (1984). The XIVth Dalai Lama: Kindness, clarity, and insight. Snow Lion Publications.

Hall, J. (1988). States and societies: The miracle in comparative perspective. In J. Baechler, J. A. Hall, \& M. Mann (Eds.), Europe and the rise of capitalism (pp. 20-38). Blackwell.

Hall, E., \& Hall, M. (1990). Understanding cultural differences. Intercultural Press.

Hamilton, G. G. (1990). Patriarchy, patrimonialism, and filial piety: A comparison of China and Western Europe. British Journal of Sociology, 41(1), 77-104.

Hannah, S. T., Thompson, R. L., \& Herbst, K. C. (2020). Moral identity complexity: Situated morality within and across work and social roles. Journal of Management, 46(5), 726-757.

Hofstede, G. (1980). Culture's consequences: International differences in work-related values. Sage Publications.

Hofstede, G., \& Bond, M. H. (1988). The Confucius connection: From cultural roots to economic growth. Organizational Dynamics, 16(4), 4-21.

Huang, C.-C., Lu, L.-C., You, C.-S., \& Yen, S.-W. (2012). The impacts of ethical ideology, materialism, and selected demographics on consumer ethics: An empirical study in China. Ethics \& Behavior, 22(4), 315-331.

Husted, B. W., \& Allen, D. B. (2008). Toward a model of cross-cultural business ethics: The impact of individualism and collectivism on the ethical decision-making process. Journal of Business Ethics, 82(2), 293-305.

Hwang, K. K. (1987). Face and favor: The Chinese power game. American Journal of Sociology, 92(4), 944-974.

Hwang, K. K. (2011). The mandala model of self. Psychological Studies, 56(4), 329-334.

Hwang, K. K. (2012). Foundations of Chinese psychology: Confucian social relations. Springer Science \& Business Media. 
Hwang, K. K., \& Chang, J. (2009). Self-cultivation: Culturally sensitive psychotherapies in Confucian societies. The Counseling Psychologist, 37(7), 1010-1032.

Ip, P. K. (2009a). Developing a concept of workplace well-being for Greater China. Social Indicators Research, 91(1), 59-77.

Ip, P. K. (2009b). Is Confucianism good for business ethics in China? Journal of Business Ethics, 88(3), 463-476.

Jennings, P. L., Mitchell, M. S., \& Hannah, S. T. (2015). The moral self: A review and integration of the literature. Journal of Organizational Behavior, 36(S1), S104-S168.

Jensen, L. C., \& Wygant, S. A. (1990). The developmental self-valuing theory: A practical approach for business ethics. Journal of Business Ethics, 9(3), 215-225.

Johansen, B.-C.P., \& Gopalakrishna, D. (2006). A Buddhist view of adult learning in the workplace. Advances in Developing Human Resources, 8(3), 337-345.

Joosten, A., Van Dijke, M., Van Hiel, A., \& De Cremer, D. (2014). Being "in control" may make you lose control: The role of selfregulation in unethical leadership behavior. Journal of Business Ethics, 121(1), 1-14.

Jordan, J., Mullen, E., \& Murnighan, J. K. (2011). Striving for the moral self: The effects of recalling past moral actions on future moral behavior. Personality and Social Psychology Bulletin, 37(5), 701-713.

Kilduff, G. J., Galinsky, A. D., Gallo, E., \& Reade, J. J. (2016). Whatever it takes to win: Rivalry increases unethical behavior. Academy of Management Journal, 59(5), 1508-1534.

Kleinen, J. (1999). Facing the future, reviving the past: A study of social change in a Northern Vietnamese village. Institute of Southeast Asian Studies.

Kohlberg, L. (1969). Stage and sequence: The cognitive developmental approach to socialization. In D. A. Goslin (Ed.), Handbook of socialization theory and research (pp. 347-480). Rand McNally.

Kohlberg, L. (1971). Stages of Moral development as a basis for moral education. In C. M. Beck, B. S. Crittenden, \& E. V. Sullivan (Eds.), Moral education: Interdisciplinary approaches (pp. 23-92). University of Toronto Press.

Kohlberg, L. (1984). The psychology of moral development: The nature and validity of moral stages (Vol. 2). Harper \& Row.

Lacan, J. (1977). The four fundamental concepts of psychoanalysis: The seminar of Jacques Lacan Book XI. Hogarth Press and Institute of Psycho-Analysis.

Lapsley, D. K., \& Hill, P. L. (2009). The development of the moral personality. In D. Narvaez, \& D. K. Lapsley (Eds.), Moral personality, identity and character: Explorations in moral psychology (pp. 185-213). Cambridge University Press.

Leshkowich, A. M. (2006). Woman, Buddhist, entrepreneur: Gender, moral values, and class anxiety in late socialist Vietnam. Journal of Vietnamese Studies, 1(1-2), 277-313.

Li, C. (2006). The Confucian ideal of harmony. Philosophy East and West, 56(4), 583-603.

Lin, L. H., Ho, Y. L., \& Lin, W. H. E. (2013). Confucian and Taoist Work Values: An exploratory study of the Chinese transformational leadership behavior. Journal of Business Ethics, 113(1), 91-103.

Logsdon, J. M., \& Wood, D. J. (2005). Global business citizenship and voluntary codes of ethical conduct. Journal of Business Ethics, 59(1-2), 55-67.

Lu, L.-C., \& Lu, C.-J. (2010). Moral philosophy, materialism, and consumer ethics: An exploratory study in Indonesia. Journal of Business Ethics, 94(2), 193-210.

Luong, H. V. (1993). Economic reform and the intensification of rituals in two North Vietnamese villages, 1980-90. In B. Ljunggren (Ed.), The challenge of reform in Indochina (pp. 259-291). Harvard Institute for International Development.
Magid, B. (2003). Your ordinary mind. In J. Safran (Ed.), Psychoanalysis and Buddhism: An Unfolding Dialogue (pp. 35-79). Somerville, MA: Wisdom Publications.

Main, J. L., \& Lai, R. (2013). Introduction: Reformulating "Socially Engaged Buddhism" as an analytical category. The Eastern Buddhist, 44(2), 1-34.

Malarney, S. K. (2003). Return to the past? The dynamics of contemporary religious and ritual transformation. In H. V. Luong (Ed.), Postwar Vietnam: Dynamics of a Transforming Society (pp. 225-256). Institute of Southeast Asian Studies and Rowman and Littlefield.

Mann, S. (1987). Local merchants and the Chinese bureaucracy, 17501950. Stanford University Press.

Markus, H. R., \& Kitayama, S. (1998). The cultural psychology of personality. Journal of Cross-Cultural Psychology, 29(1), 63-87.

Marques, J. (2010). Toward greater consciousness in the 21 st century workplace: How Buddhist practices fit in. Journal of Business Ethics, 92(2), 211-225.

Marques, J. (2012). Consciousness at work: A review of some important values, discussed from a Buddhist perspective. Journal of Business Ethics, 105(1), 27-40.

Maslow, A. (1943). A theory of human motivation. Psychological Review, 50(4), 370-396.

Maslow, A. (1954). Motivation and personality. Harper \& Row.

Mayring, P. (2000). Qualitative Content Analysis. Forum: Qualitative Social Research, 1(2).

Metcalf, L., \& Benn, S. (2012). The corporation is ailing social technology: Creating a 'fit for purpose' design for sustainability. Journal of Business Ethics, 111(2), 195-210.

Metcalf, L., \& Benn, S. (2013). Leadership for sustainability: An evolution of leadership ability. Journal of Business Ethics, 112(3), 369-384.

Meyer, E. (2014). The culture map. Public Affairs.

Michaelson, C. (2019). A normative meaning of meaningful work. Journal of Business Ethics. https://doi.org/10.1007/ s10551-019-04389-0.

Nguyen, T. (2009). Social activities of Vietnamese Buddhism in relation to charity. Religious Studies Review, 3(1 \& 2), 47-63.

OECD. (2017). Employment by enterprise size. In OECD (Ed.), Entrepreneurship at a Glance 2017. OECD Publishing.

Pace, S. (2013). Does religion affect the materialism of consumers? An empirical investigation of Buddhist ethics and the resistance of the self. Journal of Business Ethics, 112(1), 25-46.

Paik, Y., Lee, J. M., \& Pak, Y. S. (2019). Convergence in international business ethics? A comparative study of ethical philosophies, thinking style, and ethical decision-making between US and Korean managers. Journal of Business Ethics, 156(3), 839-855.

Palazzo, G., \& Scherer, A. G. (2006). Corporate legitimacy as deliberation: A communicative framework. Journal of Business Ethics, 66(1), 71-88.

Paul, P., Roy, A., \& Mukhopadhyay, K. (2006). The impact of cultural values on marketing ethical norms: A study in India and the United States. Journal of International Marketing, 14(4), 28-56.

Pham, T. T. T., \& Nguyen, T. D. (2017). Development characteristics of SME sector in Vietnam: Evidence from the Vietnam enterprise census 2006-2015. Vietnam Institute for Economic and Policy Research

Piaget, J. (1932/1977). The moral judgment of the child (M. Gabain, Trans.). Penguin.

Pope, C., Ziebland, S., \& Mays, N. (2006). Analysing qualitative data. In C. Pope, \& N. Mays (Eds.), Qualitative research in health care (3rd ed., pp. 63-81). Blackwell.

Pye, L. W. (1992). The spirit of Chinese politics. Harvard University Press. 
Ralston, D. A. (2008). The crossvergence perspective: Reflections and projections. Journal of International Business Studies, 39(1), $27-40$.

Reed, A., Aquino, K., \& Levy, E. (2007). Moral identity and judgments of charitable behaviors. Journal of Marketing, 71(1), 178-193.

Rest, J. R. (1983). Morality. In P. Mussen, J. Flavell, \& E. Markman (Eds.), Handbook of child psychology: Cognitive development (Vol. 3, pp. 556-629). Wiley.

Reynolds, S. J., Leavitt, K., \& DeCelles, K. A. (2010). Automatic ethics: The effects of implicit assumptions and contextual cues on moral behavior. Journal of Applied Psychology, 95(4), 752.

Riesebrodt, M. (2007). Cultus und Heilsversprechen: Eine Theorie der Religionen. CH Beck.

Rinpoche, P. (1993). The Heart treasure of the enlightened ones: The practice of view, meditation, and action. Shambhala Publications.

Romar, E. J. (2004a). Globalization, ethics, and opportunism: A Confucian view of business relationships. Business Ethics Quarterly, 14(4), 663-678.

Romar, E. J. (2004b). Managerial harmony: The Confucian ethics of Peter F. Drucker. Journal of Business Ethics, 51(2), 199-210.

Rosemont, H. (1988). Why take rights seriously? A Confucian critique. In L. S. Rouner (Ed.), Human rights and the world's religions (pp. 167-182). University of Notre Dame Press.

Sachdeva, S., Iliev, R., \& Medin, D. L. (2009). Sinning saints and saintly sinners: The paradox of moral self-regulation. Psychological Science, 20(4), 523-528.

Savur, S., Provis, C., \& Harris, H. (2018). Ethical decision-making in Australian SMEs: A field study. Small Enterprise Research, 25(2), 114-136.

Schuyler, K. G. (2012). Inner peace global impact: Tibetan Buddhism, leadership, and work. IAP.

Schwarz, N. (1990). Feelings as information: Informational and motivational functions of affective states. In E. T. Higgins \& R. M. Sorrentino (Eds.), Handbook of motivation and cognition: Foundations of social behavior (Vol. 2, pp. 527-561). The Guilford Press.

Schwartz, S. H. (1992). Universals in the content and structure of values: Theoretical advances and empirical tests in 20 countries. Advances in Experimental Social Psychology, 25(1), 1-65.

Schwartz, S. H. (1994). Beyond individualism/collectivism: New cultural dimensions of values. In U. Kim, H. C. Triandis, C. Kagitcibasi, S. C. Choi, \& G. Yoon (Eds.), Individualism and collectivism: Theory, method and applications (pp. 85-119). Sage.

Shiah, Y.-J. (2016). From self to nonself: The nonself theory. Frontiers in Psychology, 7, 124.

Shonin, E., Van Gordon, W., \& Griffiths, M. D. (2014). The emerging role of Buddhism in clinical psychology: Toward effective integration. Psychology of Religion and Spirituality, 6(2), 123.

Shonin, E., Van Gordon, W., \& Griffiths, M. D. (2016). Ontological addiction: Classification, etiology, and treatment. Mindfulness, 7(3), 660-671.

Shweder, R. A., Goodnow, J. J., Hatano, G., LeVine, R. A., Markus, H. R., \& Miller, P. J. (1998). The cultural psychology of development: One mind, many mentalities. In W. Damon (Ed.), Handbook of child psychology (Vol. 1). Wiley.

Silverman, D. (2013). Doing qualitative research: A practical handbook (4th`ed.): Sage Publications Limited.

Sim, M. (2007). Remastering morals with Aristotle and Confucius. Cambridge University Press.

SME Administration Taiwan. (2019). 2019 White paper on small and medium enterprises in Taiwan. Retrieved September 17, 2020, from https://www.moeasmea.gov.tw
Stake, R. (2000). Case studies. In N. K. Denzin, \& Y. Lincoln (Eds.), Handbook of qualitative research (pp. 435-454). Sage Publications Inc.

Steyrer, J. (2002). Stigma and charisma and the narcissistic personality. In B. J. Avolio, \& F. J. Yammarino (Eds.), Transformational and charismatic leadership: The road ahead (pp. 231-254). AI Press.

Streng, F. J. (1967). Emptiness: A study in religious meaning. Nashville: Abingdon Press.

Suddaby, R., Bitektine, A., \& Haack, P. (2017). Legitimacy. Academy of Management Annals, 11(1), 451-478.

Sundararajan, L. (2005). Happiness donut: A Confucian critique of positive psychology. Journal of Theoretical and Philosophical Psychology, 25(1), 35-60.

Ta, V. T. (1989). Buddhism and human rights in traditional Vietnam. Review of Vietnamese Studies, 2, 50-67.

Taylor, P. (2004). Goddess on the rise: Pilgrimage and popular religion in Vietnam. University of Hawaii Press.

Thondup, T. (1995). Enlightened journey: Buddhist practice as daily life (Vol. 19). Shambhala Publications.

Thurman, R. (2005). The jewel tree of Tibet: The enlightenment engine of Tibetan Buddhism. Simon and Schuster.

Topmiller, R. (2000). Vietnamese Buddhism in the 1990s. CrossCurrents, 50, 232-239.

Van Gordon, W., Shonin, E., \& Griffiths, M. D. (2016). Buddhist emptiness theory: Implications for psychology. Psychology of Religion and Spirituality, 9(4), 309.

Vu, M. C. (2019). Tensions and struggles in tackling bribery at the firm level: Perspectives from Buddhist-enacted organizational leaders. Journal of Business Ethics. https://doi.org/10.1007/ s10551-019-04235-3.

Vu, M. C., \& Gill, R. (2018). Is there corporate mindfulness? An exploratory study of Buddhist-enacted spiritual leaders' perspectives and practices. Journal of Management, Spirituality \& Religion, 15(2), 155-177.

Vu, M. C., \& Tran, T. (2019). Trust issues and engaged Buddhism: The triggers for skillful managerial approaches. Journal of Business Ethics. https://doi.org/10.1007/s10551-019-04273-x.

Vu, M. C., Wolfgramm, R., \& Spiller, C. (2018). Minding less: Exploring mindfulness and mindlessness in organizations through skillful means. Management Learning, 49(5), 578-594.

Waddock, S. (2001). Leading corporate citizens: Meeting the business and society challenge. McGraw-Hill Irwin.

Whitley, R. (1999). Divergent capitalisms: The social structuring and change of business systems. Oxford University Press.

Woods, P. R., \& Lamond, D. A. (2011). What would Confucius do?Confucian ethics and self-regulation in management. Journal of Business Ethics, 102(4), 669-683.

$\mathrm{Wu}, \mathrm{M}$. (2017). The process of self-cultivation and the mandala model of the self. Frontiers in Psychology, 8, 24.

Yao, X. (2000). An introduction to Confucianism. Cambridge University Press.

Yin, R. K. (2018). Case study research and applications: Design and methods (6th ed.). Sage Publications Inc.

Yoneyama, E. (2007). Phenomenology of life, Zen and management. Society and Business Review, 2(2), 204-217.

Yu, J. (2007). The ethics of Confucius and Aristotle: Mirrors of virtue. Routledge.

Zhu, Y. (2015). The role of Qing (positive emotions) and Li (rationality) in Chinese entrepreneurial decision making: A Confucian RenYi wisdom perspective. Journal of Business Ethics, 126(4), 613.

Publisher's Note Springer Nature remains neutral with regard to jurisdictional claims in published maps and institutional affiliations. 